$10.1590 / \mathrm{S} 1414-40772018000300004$

Este é um artigo publicado em acesso aberto sob uma licença Creative Commons

https://creativecommons.org/licenses/by-nc/4.0/

\title{
Autoavaliação institucional: construção e validação de um questionário para o professor
}

\author{
Girlene Ribeiro de Jesus ${ }^{1}$
}

Amanda Guedes Andrade Bedritichuk ${ }^{2}$

Resumo: O presente estudo tem como objetivo construir e validar um questionário que contemple a percepção docente no processo de autoavaliação institucional da Universidade de Brasília. Para tanto, foram considerados os eixos do Sistema Nacional de Avaliação da Educação Superior (Sinaes), foi realizada pesquisa bibliográfica e um grupo focal foi conduzido com docentes. Com base nas informações obtidas foi elaborada uma primeira versão do questionário, que passou por um refinamento por meio da avaliação de seis juízes. A versão final do instrumento foi enviada pela internet aos docentes da UnB. Os resultados indicaram relevantes evidências de validade da estrutura composta por três fatores: Infraestrutura física; Planejamento, Avaliação, Desenvolvimento e Gestão Institucional e Políticas acadêmicas e gestão do corpo docente. Conclui-se, que o questionário de autoavaliação institucional a ser respondido pelo docente apresentou evidências suficientes para ser incorporado ao processo de autoavaliação da Universidade de Brasília.

Palavras-chave: Auto-avaliação institucional. Sinaes. Avaliação docente.

\section{Institutional self-evaluation: constructing and validating a professor questionnaire}

Abstract: This study aims to construct and validate a questionnaire that considers the professor's perception in the institutional self-evaluation process at University of Brasilia. Therefore, Sinaes axes, bibliography research and a focus group with professors were considered. Based on this information we constructed a preliminary version of the questionnaire, which was refined by the assessment of six judges. The questionnaire final version was sent by Internet to UnB professors. The results indicate important validity evidences of structure composed by three factors: Physical Infrastructure; Planning, Evaluation, Development and Institutional Management and Academic politics and professor management. We conclude that the institutional self-evaluation questionnaire to be answered by the professors presented sufficient evidence to be incorporated to University of Brasilia self-evaluation process.

Key words: Institutional self-evaluation. Sinaes. Professor evaluation. 


\section{Introdução}

Em novembro de 2013, uma comissão de avaliadores externos do Ministério da Educação visitou a Universidade de Brasília (UnB) com o objetivo de avaliar o curso de ciências biológicas. Como de costume, a comissão fez uma série de diligências: visita à biblioteca, averiguação das instalações do instituto, reunião com os alunos, entrevistas com os professores, com o núcleo docente estruturante do curso e, finalmente, reunião com a Comissão Própria de Avaliação da UnB - CPA.

$\mathrm{Na}$ ocasião, os membros da CPA ouviram uma pergunta que era recorrente em visitas desse tipo: "quais são os procedimentos institucionais que a UnB utiliza para ouvir alunos, docentes e técnicos?". Surpreendentemente, uma universidade do tamanho e do porte da UnB apenas fazia consulta de avaliação aos alunos. Não havia, até aquela data, nenhum instrumento que captasse a opinião dos docentes e dos técnicos no ciclo avaliativo, ou seja, o processo de autoavaliação necessitava ser aprimorado visando atender aos propósitos do Sistema Nacional de Avaliação da Educação Superior (Sinaes).

O Sinaes foi criado por meio da Lei ${ }^{\circ} 10.861$ de 2004, quando o conceito de avaliação passou a ser visto de forma global e integradora, conjugando diversos instrumentos, em diferentes momentos de aplicação e, sobretudo, a articulação entre a avaliação e a regulação. A avaliação passou a cumprir, neste contexto, a eficácia do ponto de vista da relevância social e da pertinência essenciais à construção da qualidade no sistema de educação superior (DIAS SOBRINHO, 2010). A regulação se configurou nas modalidades de credenciamento e recredenciamento periódicos das IES e autorização, reconhecimento e renovação de reconhecimento dos cursos.

O Sinaes é fundamentado em princípios e objetivos vinculados à missão social da educação superior e reúne uma série de mecanismos avaliativos, com a proposta de nivelar as Instituições de Ensino Superior (IES) em termos de qualidade (POLIDORI; MARINHOARAUJO; BARREYRO, 2006).

Dentro do Sinaes são avaliadas três componentes: cursos, estudantes e instituições. A componente de cursos é sistematizada pela componente da avaliação dos Cursos de Graduação (ACG). O segmento institucional, por sua vez, ficou a cargo da componente da avaliação das instituições de educação superior - Avalies (que engloba a autoavaliação institucional e a avaliação externa). Finalmente, a vertente “estudantes” é aferida pelo Exame Nacional de Desempenho dos Estudantes - Enade. 
$\mathrm{Na}$ avaliação da instituição, instrumentalizada pelo Avalies, são verificados, por exemplo, a infraestrutura, as políticas para a carreira docente, as políticas de ensino, o Plano de Desenvolvimento Institucional - PDI, o Projeto Político Pedagógico - PPP, a adequação aos parâmetros curriculares nacionais, entre outros. Trata-se, portanto, de questões internas à instituição de ensino superior, apuradas tanto pela autoavaliação, quanto pela avaliação externa.

Verifica-se, desse modo, que a autoavaliação proporciona uma visão interna não captada pelas outras componentes do Sinaes. Representa não somente uma janela para o autoconhecimento, como também a possibilidade de a própria instituição rever e atualizar suas metas. A autoavaliação institucional é um processo capaz de produzir uma reflexão coletiva acerca da realidade institucional, rediscutir projetos e prioridades essenciais da Universidade, suas relações com a ciência, a tecnologia, as letras, as artes e suas interações com a sociedade, contribuindo para a sistematização mais consistente dos diversos propósitos da instituição.

Representa ainda uma oportunidade para a tomada de decisão e de consciência institucional, a partir da reflexão coletiva que os próprios sujeitos organizacionais produzem sobre o conjunto de atividades institucionais (QUEIROZ, 2011).

A prática da autoavaliação está associada também ao processo de construção da própria autonomia institucional, concorrendo para o desenvolvimento profissional de professores, melhorias no processo pedagógico e na organização (MENEZES, 2012).

Segundo Belloni et al. (2008, p. 101), esse processo tem por objetivo “a ampliação do autoconhecimento da instituição sobre si mesma em busca de melhor adequação ao cumprimento de suas funções científicas e sociais".

A autoavaliação institucional representa componente basilar no processo decisório das IES, na medida em que concebe uma discussão coletiva sobre a instituição pelos sujeitos que a compõem, conferindo legitimidade, autonomia e significado a essa análise. Na dinâmica de avaliação concebida pelo Sinaes, pode-se perceber a autoavaliação como componente central do sistema avaliativo, uma tentativa de resgate à cultura formativa de avaliação, já que "é neste momento que as instituições têm maiores possibilidades de apresentar suas considerações e realizar uma construção mais coletiva de suas ações e reflexões” (MENEZES, 2012, p. 82).

Diante dessa proeminência, faz-se mister que o processo de autoavaliação tenha representatividade de todos os segmentos da comunidade acadêmica, quais sejam: docentes, discentes e servidores técnico-administrativos. O processo precisa ainda agregar a esses segmentos a participação da comunidade externa, distanciando-se do caráter endógeno que uma avaliação desse tipo pudesse apresentar (BELLONI et al., 2008). 
A autoavaliação representa um processo de aprendizagem e propicia à sociedade o acesso ao cenário da Instituição, construído pelos próprios componentes da comunidade universitária e representantes da sociedade civil.

A Figura 1, a seguir, representa os cinco eixos de autoavaliação propostos pela nota técnica INEP/DAES/CONAES nº 65 (BRASIL, 2014).

\section{Figura 1 - Os cinco eixos da autoavaliação propostos}

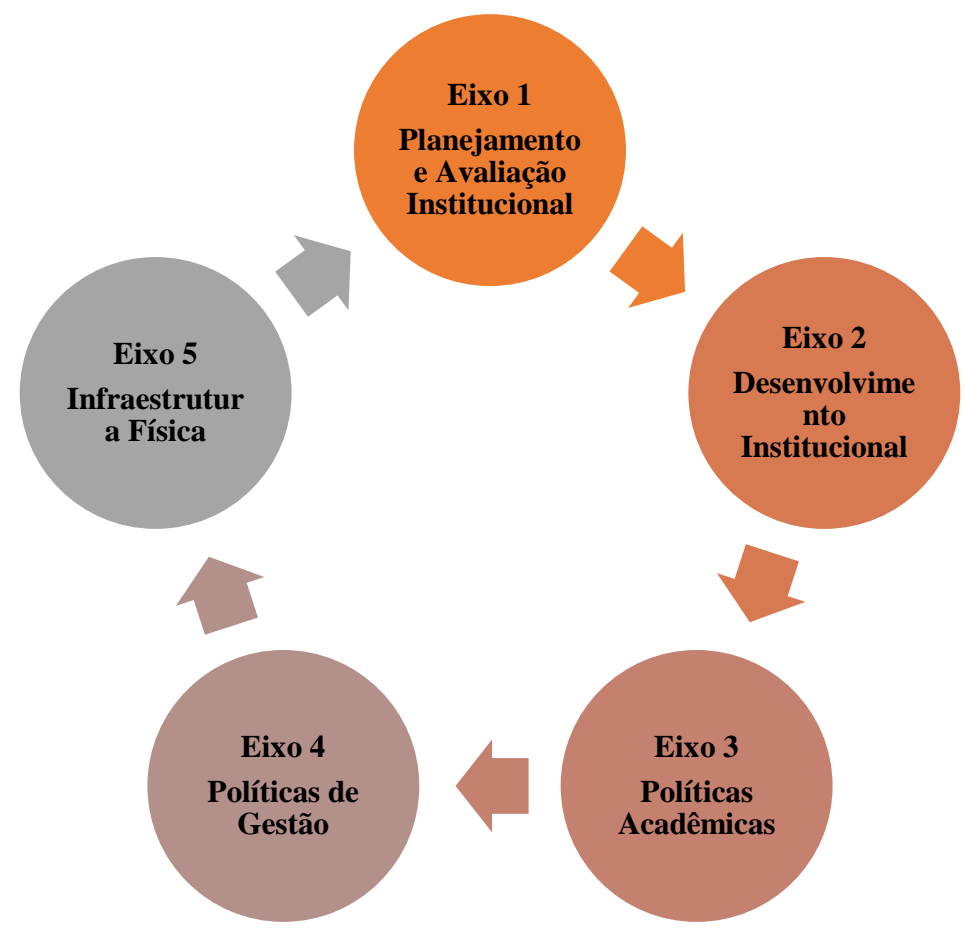

Fonte: BEDRITICHUK. A. G. A. Um instrumento de avaliação docente para a Universidade de Brasília: uma construção nos moldes do Sinaes. 2015. Dissertação (Mestrado em Educação) - Faculdade de Educação, Universidade de Brasília, Brasília, 2015.

A autoavaliação institucional é estabelecida sob os aspectos representados na Figura 1 e detalhados na sequência.

a) Objeto: $O$ objeto da autoavaliação institucional corresponde aos cinco eixos de avaliação determinados pela nota técnica INEP/DAES/CONAES n ${ }^{\circ} 65$ (BRASIL, 2014), que corresponde a uma compilação das dez dimensões definidas pelo documento original do Sinaes.

b) Sujeitos da avaliação: docentes, discentes, funcionários e comunidade externa.

A incompletude do processo de autoavaliação da UnB, por não envolver toda a comunidade acadêmica, deixa de atender exigências legais expressas sobre o processo de 
valiação da educação superior. A UnB, instituição de vanguarda e referência ${ }^{1}$, encontra-se neste ponto atrás de diversas outras universidades federais brasileiras. Cerca de três quintos das universidades federais já adotam instrumentos de autoavaliação para alunos, docentes e técnicos.

É motivada por essa lacuna que surgiu a presente pesquisa, propondo-se a contribuir para o envolvimento do segmento docente no processo de autoavaliação da UnB. Seja porque são protagonistas do processo de ensino e aprendizagem, seja pelo tempo de vivência na universidade, os docentes constituem opinião valorosa para a autoavaliação.

Assim, o objetivo geral dessa pesquisa foi propor um questionário de autoavaliação adequado à realidade do docente da educação superior.

\section{Método}

O método misto foi o utilizado na presente pesquisa, ou seja, foram empregados elementos da abordagem qualitativa e quantitativa. A abordagem qualitativa compreende a interpretação dos fatos a partir de observações, entrevistas e análise de documentos. Esse tipo de abordagem se justifica por ajudar a compreender aspectos psicológicos, que não podem ser apreendidos por outros métodos (RICHARDSON, 2014). No que tange à abordagem quantitativa, foram utilizadas as técnicas da análise exploratória de dados, análise fatorial e de amostragem.

Inicialmente, foi realizada revisão da literatura e de outros instrumentos semelhantes, na sequência foi realizada uma pesquisa exploratória, tendo como ferramenta de coleta de dados o grupo focal. O produto final da parte exploratória se deu na forma de um roteiro com questões úteis para captar a opinião do docente no processo autoavaliativo da UnB.

Após essa fase, promoveu-se a compilação das variáveis determinantes para o modelo de avaliação docente a partir da análise de conteúdo feita por juízes e da aplicação do questionário analisado pelos juízes a uma amostra representativa dos docentes da universidade.

No que se refere à dimensão do tempo, o recorte foi transversal, adequado aos estudos realizados uma única vez pelo pesquisador, representando o quadro de determinado momento, principalmente na presença de restrições orçamentárias e de tempo.

\footnotetext{
${ }^{1}$ Primeira Universidade a ser constituída na forma de Fundação Pública, a primeira universidade a instituir o sistema de cotas, o Programa de Avaliação Seriada como forma de ingresso.
} 


\section{Amostra}

As amostras delineadas para esse estudo compreenderam:

a) amostra de seis docentes do quadro da Universidade de Brasília para a composição do grupo focal, observando-se a representatividade das diversas grandes áreas do conhecimento. Ressalta-se que vários participantes do Grupo Focal têm vasta experiência na área de avaliação, sendo alguns deles membros da CPA ou estudiosos da construção de escalas psicométricas.

b) amostra de seis professores da UnB na etapa de validação semântica e de conteúdo do instrumento. A amostra foi composta por professores doutores, que possuem afinidade com o tema da educação superior e construção de instrumentos e escalas psicométricas.

c) amostra estratificada de docentes pelos institutos e faculdades para a etapa da averiguação de evidências de validade com base na estrutura interna do instrumento, cada estrato $n_{i}$ definido observando-se o cálculo (COCHRAN, 1977):

$n_{i}=\frac{n}{N} * N_{i}$, onde:

$n=$ tamanho da amostra

$N=$ tamanho da população

$N_{i}=$ tamanho do estrato (quantitativo de docentes no instituto ou faculdade)

$\frac{n}{N}=f=$ fração amostral

A amostragem estratificada é indicada quando é fácil o acesso à lista contendo todos os elementos da população, e embora seja heterogênea, pode-se identificar grupos homogêneos que compõem diferentes estratos ${ }^{2}$ (COCHRAN, 1977).

Diante do exposto, estipulou-se, como meta, obter uma amostra correspondente a $10 \%$ do universo docente na UnB (composto por 2.397 docentes), percentual razoável para o processamento das análises. Dessa forma, esperou-se a resposta de 250 docentes para a fase de averiguação de evidências de validade do instrumento proposto.

A despeito de o plano amostral demandar 250 respostas, a amostra obtida foi de 396, o que correspondeu a 16,5\% dos docentes da UnB, satisfazendo assim as condições para o tamanho aceitável de amostra e processamento da análise fatorial que, segundo Hair et al. (2009) deve ser de, no mínimo, 100 sujeitos.

\footnotetext{
${ }^{2}$ A garantia da aleatoriedade dentro de cada estrato não pôde ser observada dado tratar-se de uma pesquisa na área social, onde contou-se com o voluntariado na obtenção das respostas.
} 
Dessa forma, o tamanho da amostra superou em 146 o número esperado de devolutivas, o que sugere a produção de resultados mais precisos, mais próximos dos índices populacionais e com erros amostrais menores, tanto no que tange à estrutura fatorial, quanto às comunalidades (DAMÁSIO, 2012).

O quantitativo de docentes respondentes se distribuiu entre os institutos e faculdades de acordo com o observado na Tabela 1, a seguir.

\section{Tabela 1 - Quantitativo esperado e obtido de docentes por instituto ou faculdade}

\begin{tabular}{|c|c|c|c|}
\hline Instituto ou Faculdade & Esperado & Obtido & $\%$ obtido \\
\hline Faculdade de Agronomia e Medicina Veterinária & 9 & 12 & 133 \\
\hline Faculdade de Arquitetura e Urbanismo & 7 & 9 & 129 \\
\hline Faculdade de Ciência da Informação & 4 & 8 & 200 \\
\hline Faculdade de Saúde & 18 & 28 & 156 \\
\hline Faculdade de Comunicação & 4 & 9 & 225 \\
\hline Faculdade de Direito & 6 & 9 & 150 \\
\hline Faculdade de Economia, Administração e Contabilidade & 13 & 35 & 269 \\
\hline Faculdade de Educação & 11 & 14 & 127 \\
\hline Faculdade de Educação Física & 4 & 10 & 250 \\
\hline Faculdade de Medicina & 10 & 10 & 100 \\
\hline Faculdade de Tecnologia & 20 & 30 & 150 \\
\hline Faculdade UnB Ceilândia & 14 & 24 & 171 \\
\hline Faculdade UnB Gama & 12 & 15 & 125 \\
\hline Faculdade UnB Planaltina & 10 & 11 & 110 \\
\hline Instituto de Artes & 12 & 14 & 117 \\
\hline Instituto de Ciência Política & 3 & 5 & 167 \\
\hline Instituto de Ciências Biológicas & 15 & 27 & 180 \\
\hline Instituto de Ciências Exatas & 14 & 17 & 121 \\
\hline Instituto de Ciências Humanas & 13 & 29 & 223 \\
\hline Instituto de Ciências Sociais & 5 & 9 & 180 \\
\hline Instituto de Física & 7 & 9 & 129 \\
\hline Instituto de Geociências & 5 & 11 & 220 \\
\hline Instituto de Letras & 15 & 15 & 100 \\
\hline Instituto de Psicologia & 5 & 12 & 240 \\
\hline Instituto de Química & 6 & 8 & 133 \\
\hline Instituto de Relações Internacionais & 2 & 4 & 200 \\
\hline Centros & 3 & 4 & 133 \\
\hline Gestão & 3 & 3 & 100 \\
\hline Outros & 0 & 5 & - \\
\hline Total & 250 & 396 & 158 \\
\hline
\end{tabular}

Fonte: Elaboração própria

Quando segmentados por sexo, os respondentes foram 56\% homens e 44\% mulheres, valores próximos aos verificados na população de docentes na UnB (55\% e 45\%, respectivamente).

Acerca do tipo de vínculo, 391 respondentes se declararam professores efetivos, 2 substitutos e 3 não responderam à questão. Com relação à jornada de trabalho, 368 são de dedicação exclusiva, quase $93 \%$ dos respondentes. 
O nível de titulação dos respondentes está descrito na Tabela 2 e revela o percentual de $85 \%$ de doutores entre os respondentes, valor próximo ao verificado na população, de $86 \%$.

Tabela 2 - Respondentes por nível de titulação

\begin{tabular}{ccccc}
\hline Nível de titulação & $\begin{array}{c}\text { Frequência } \\
\text { esperada }\end{array}$ & \% esperado & $\begin{array}{c}\text { Frequência } \\
\text { obtida }\end{array}$ & \% obtido \\
\hline Doutorado & 341 & 86 & 337 & 85 \\
Especialização & 3 & 1 & 3 & 1 \\
Mestrado & 52 & 13 & 49 & 12 \\
Total & 396 & 100 & 396 & 100 \\
\hline
\end{tabular}

Fonte: Elaboração própria

Quando perguntados sobre o tempo de magistério na UnB, os docentes responderam de acordo com o Gráfico 1.

\section{Gráfico 1 - Respondentes por tempo de magistério na UnB}

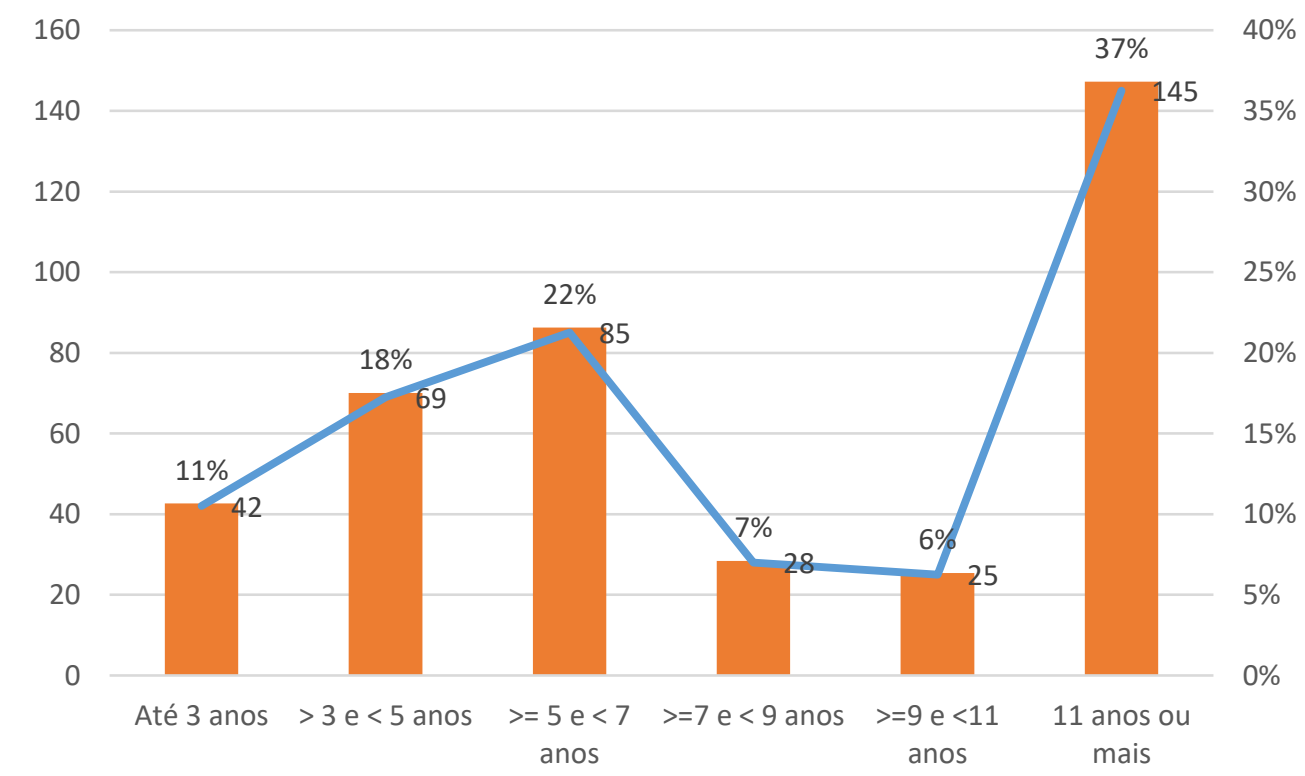

Fonte: Elaboração própria

\section{Instrumentos}

O procedimento para a construção do questionário utilizou como referência os trabalhos de Santos e Laros (2007) e Bandeira et al. (1998) e está representado na Figura 2. Vale ressaltar que se trata de um modelo de retroalimentação. 
Figura 2 - Modelo para a construção do instrumento

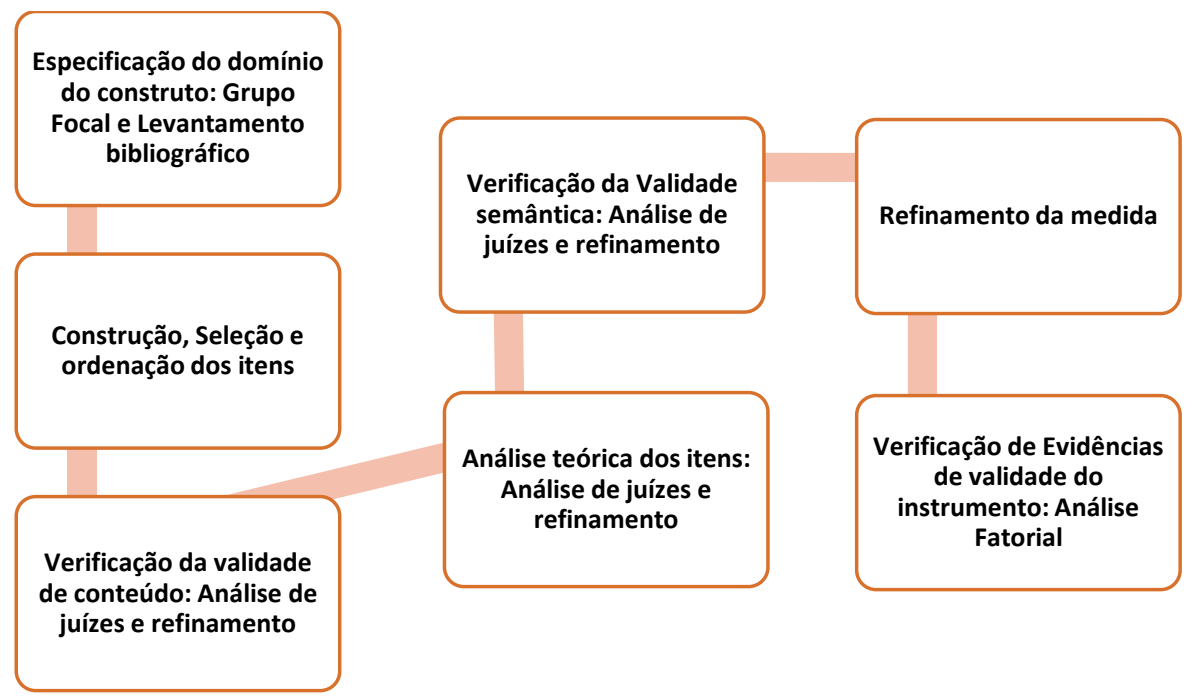

Fonte: SANTOS, L. F. B. P. dos; LAROS, J. A. Avaliação da prática pedagógica do professor de ensino superior. Estudos em Avaliação Educacional, Brasília, n. 36, v. 18, p. 75-96, jan./abr. 2007; BANDEIRA, M. L. et al. Avaliação da qualidade do ensino de pós-graduação: elementos para a construção e validação de um instrumento de pesquisa. In: ENANPAD, 22, 1998, Foz do Iguaçu. Anais... Rio de Janeiro: ANPAD, 1998.

\section{a) Grupo focal}

No grupo focal, o docente foi incentivado a relatar sua percepção, como ele vê na universidade cada um dos temas: Planejamento e Avaliação Institucional; Desenvolvimento Institucional; Políticas Acadêmicas; Políticas de Gestão e Infraestrutura Física. O roteiro se baseou ainda no Instrumento de Avaliação Institucional Externa para os atos de Credenciamento, Recredenciamento e Transformação de Organização Acadêmica, na modalidade presencial.

O resultado da análise de conteúdo das informações obtidas no grupo e do levantamento bibliográfico produziu uma série de 67 itens para os seis blocos em questão: Perfil do Docente, Planejamento e Avaliação Institucional, Desenvolvimento Institucional, Políticas Acadêmicas, Políticas de Gestão e Infraestrutura Física. O questionário proveniente dessa fase foi submetido ao julgamento de seis juízes.

\section{b) Análise de juízes}

O formulário resultante da discussão do grupo focal e do levantamento das variáveis a partir do instrumento de avaliação institucional externa foi submetido à análise de juízes (docentes doutores em avaliação da educação superior e/ou construção de escalas 
psicométricas). O resultado do julgamento, quanto à clareza e representatividade, está descrito na Tabela 3.

\section{Tabela 3 - Resultado da Análise de Juízes}

\begin{tabular}{|c|c|c|}
\hline Temas & Representatividade & Clareza \\
\hline \multicolumn{3}{|l|}{ Infraestrutura } \\
\hline 1. Instalações administrativas do Instituto ou Faculdade & $83 \%$ & $83 \%$ \\
\hline 2. Espaço físico destinado às aulas teóricas & $100 \%$ & $100 \%$ \\
\hline 3. Espaço físico destinado às aulas práticas & $100 \%$ & $100 \%$ \\
\hline 4. Serviços disponibilizados nos ambientes destinados às aulas práticas * & $\underline{67 \%}$ & $\underline{33 \%}$ \\
\hline 5. Quantitativo de salas de aula & $\overline{83 \%}$ & $\overline{83 \%}$ \\
\hline 6. Logística na distribuição de alunos por sala?* & $\mathbf{5 0 \%}$ & $33 \%$ \\
\hline 7. Condições gerais dos auditórios* & $\overline{100 \%}$ & $\overline{67 \%}$ \\
\hline 8. Sala destinada ao uso docente* & $83 \%$ & $\overline{67 \%}$ \\
\hline 9. Espaços para atendimento aos alunos?* & $\underline{67 \%}$ & $\overline{\mathbf{5 0 \%}}$ \\
\hline 10. Instalações sanitárias & $100 \%$ & $100 \%$ \\
\hline 11. Infraestrutura física da biblioteca & $100 \%$ & $100 \%$ \\
\hline 12. Grau de informatização da biblioteca & $100 \%$ & $83 \%$ \\
\hline 13. Serviço de atendimento da biblioteca* & $\underline{67 \%}$ & $100 \%$ \\
\hline 14. Acervo da biblioteca* & $83 \%$ & $67 \%$ \\
\hline 15. Serviços de apoio tecnológico para as aulas* & $67 \%$ & $\overline{100 \%}$ \\
\hline 16. Espaços de convivência e alimentação* & $\overline{83 \%}$ & $67 \%$ \\
\hline 17. Restaurante Universitário & $100 \%$ & $\overline{100 \%}$ \\
\hline 18. Segurança & $83 \%$ & $83 \%$ \\
\hline 19. Estacionamento & $100 \%$ & $100 \%$ \\
\hline 20. Condições de Acessibilidade no Campus? & $83 \%$ & $83 \%$ \\
\hline 21. Convergência entre recursos disponíveis e as necessidades do docente?* & $\underline{\mathbf{5 0 \%}}$ & $\underline{33 \%}$ \\
\hline \multicolumn{3}{|l|}{ Políticas de Gestão } \\
\hline 1. Percebo continuidade nas Políticas de Gestão & $100 \%$ & $100 \%$ \\
\hline 2. Considero o modelo de gestão centralizado & $83 \%$ & $83 \%$ \\
\hline 3. Considero que existe um projeto universitário consolidado & $100 \%$ & $100 \%$ \\
\hline 4. Percebo um amadurecimento técnico na elaboração das políticas de gestão & $100 \%$ & $83 \%$ \\
\hline 5. O docente é incentivado a participar da definição das políticas de gestão & $100 \%$ & $100 \%$ \\
\hline 6. Considero satisfatória a oferta de ações de capacitação de docentes & $83 \%$ & $83 \%$ \\
\hline 7. Considero satisfatória a qualidade das ações de capacitação de docentes & $83 \%$ & $83 \%$ \\
\hline 8. Considero satisfatório o sistema de registro acadêmico* & $83 \%$ & $\underline{67 \%}$ \\
\hline 9. Considero que a gestão institucional está vinculada a um planejamento & & \\
\hline financeiro* & $\underline{67 \%}$ & $\underline{67 \%}$ \\
\hline $\begin{array}{l}\text { 10. Considero que existe coerência entre o plano de carreira implantado e a } \\
\text { gestão do corpo docente }\end{array}$ & $100 \%$ & $83 \%$ \\
\hline \multicolumn{3}{|l|}{ Políticas Acadêmicas } \\
\hline 1. Na UnB existe uma política acadêmica institucional co & $83 \%$ & $100 \%$ \\
\hline 2. Percebo clareza na definição de políticas acadêmicas institucionais na UnB & $100 \%$ & $100 \%$ \\
\hline 3. Tenho domínio sobre o Projeto-Político- Pedagógico do meu curso & $100 \%$ & $100 \%$ \\
\hline 4. Para todas as disciplinas que leciono elaboro o plano de ensino & $100 \%$ & $100 \%$ \\
\hline 5. Cumpro integralmente o plano de ensino de todas as disciplinas que leciono & $100 \%$ & $100 \%$ \\
\hline 6. Considero que a UnB atende às expectativas da sociedade* & $67 \%$ & $\underline{\mathbf{5 0} \%}$ \\
\hline $\begin{array}{l}\text { 7. Considero que as atividades de ensino, pesquisa e extensão são igualmente } \\
\text { valorizadas na UnB }\end{array}$ & $100 \%$ & $100 \%$ \\
\hline 8. Tenho liberdade para definir meu plano de ensino e minha prática docente & $100 \%$ & $100 \%$ \\
\hline $\begin{array}{l}\text { 9. As ações acadêmico-administrativas implantadas convergem com as políticas } \\
\text { de ensino para os cursos de graduação? }\end{array}$ & $83 \%$ & $83 \%$ \\
\hline $\begin{array}{l}\text { 10. As ações acadêmico-administrativas implantadas convergem com as políticas } \\
\text { de ensino para os cursos de pós-graduação }\end{array}$ & $100 \%$ & $100 \%$ \\
\hline $\begin{array}{l}\text { 11. As ações acadêmico-administrativas implantadas convergem com as políticas } \\
\text { para a pesquisa, iniciação científica, tecnológica, artística e cultural* }\end{array}$ & $83 \%$ & $50 \%$ \\
\hline
\end{tabular}




\begin{tabular}{|c|c|c|}
\hline \\
\hline $\begin{array}{l}\text { 12. As ações acadêmico-administrativas implantadas de extensão são eficazes no } \\
\text { apoio à realização de programas, projetos, atividades e ações. } \\
\text { 13. Há incentivo para publicações científicas. } \\
\text { 14. Considero os meios de comunicação da UnB eficazes.* } \\
\text { 15. Os programas de apoio aos estudantes funcionam de modo satisfatório.* }\end{array}$ & $\begin{array}{l}100 \% \\
100 \% \\
\underline{\mathbf{6 7 \%}} \\
\underline{\mathbf{6 7 \%}}\end{array}$ & $\begin{array}{r}83 \% \\
100 \% \\
83 \% \\
83 \%\end{array}$ \\
\hline \multicolumn{3}{|l|}{ Desenvolvimento Institucional } \\
\hline $\begin{array}{l}\text { 1. As ações institucionais de ensino de graduação e pós-graduação estão de } \\
\text { acordo com o PDI - Plano de Desenvolvimento Institucional* } \\
\text { 2. As práticas de extensão estão de acordo com o PDI - Plano de }\end{array}$ & $83 \%$ & $\underline{67 \%}$ \\
\hline $\begin{array}{l}\text { 2. As práticas de extensão estão de acordo com o PDI - Plano de } \\
\text { Desenvolvimento Institucional* }\end{array}$ & $83 \%$ & $83 \%$ \\
\hline $\begin{array}{l}\text { 3. As atividades de pesquisa/iniciação científica, tecnológica, artística e cultural } \\
\text { estão de acordo com o PDI - Plano de Desenvolvimento Institucional* }\end{array}$ & $83 \%$ & $\underline{67 \%}$ \\
\hline 4. As ações de responsabilidade social estão de acordo com o PDI - Plano de & & \\
\hline Desenvolvimento Institucional* & $83 \%$ & $83 \%$ \\
\hline $\begin{array}{l}\text { 5. As ações institucionais para a internacionalização estão de acordo com o PDI } \\
\text { 6. Considero a UnB importante para o desenvolvimento econômico e social do }\end{array}$ & $83 \%$ & $83 \%$ \\
\hline Distrito Federal & $83 \%$ & $83 \%$ \\
\hline 7. Percebo na UnB uma rotina de normatização das práticas & $83 \%$ & $83 \%$ \\
\hline 8. A UnB possui valores institucionais bem definidos e consolidados & $100 \%$ & $100 \%$ \\
\hline \multicolumn{3}{|l|}{ Planejamento e Avaliação Institucional } \\
\hline $\begin{array}{l}\text { 1. O modelo de autoavaliação da Universidade de Brasília é suficientemente } \\
\text { conhecido }\end{array}$ & $83 \%$ & $83 \%$ \\
\hline 2. Considero o modelo de autoavaliação institucional da UnB eficaz* & $\underline{67 \%}$ & $\underline{67 \%}$ \\
\hline 3. Conheço o PDI da UnB* & $\overline{\mathbf{5 0 \%}}$ & $\overline{67 \%}$ \\
\hline 4. Considero que na UnB há suficiente divulgação do Plano de Desenvolvimento & & \\
\hline Institucional* & $\underline{67 \%}$ & $\underline{67 \%}$ \\
\hline $\begin{array}{l}\text { 5. Há envolvimento da comunidade acadêmica no processo de autoavaliação } \\
\text { institucional da UnB }\end{array}$ & $83 \%$ & $83 \%$ \\
\hline
\end{tabular}

Fonte: Elaboração própria

A Tabela 3 descreve o julgamento realizado pelos juízes durante a análise de conteúdo do instrumento. Utilizando-se o nível mínimo de concordância de $80 \%$ para aceitação quanto à representatividade e clareza do item, obteve-se os itens críticos marcados com (*). Destarte, os itens problemáticos levantados por essa análise foram revistos ou até mesmo excluídos.

A sugestão dos juízes indicou a junção das categorias 4: Planejamento e Avaliação Institucional e 5: Desenvolvimento Institucional em uma, haja vista a afinidade de temas. Dessa forma, a versão final do instrumento aplicado aos docentes ficou composto por 7 questões referentes ao perfil do docente; 22 da categoria Infraestrutura (respondidos em uma escala likert com os extremos 0- completamente inadequado a 6, completamente adequado); 16 da categoria Políticas de gestão, 14 da categoria Políticas acadêmicas e 10 da categoria Planejamento e desenvolvimento institucional (sendo essas três categorias respondidas em uma escala likert com os extremos 0 - concordo completamente a 6 , discordo completamente). Além da escala likert, havia as opções "não se aplica" e "não sei responder". 


\section{Procedimentos para coleta e análise dos dados}

O questionário resultante da análise realizada pelos juízes foi aplicado aos docentes da UnB para verificação de evidências de sua validade de construto. Para a aplicação foi utilizado o endereço eletrônico de todos os docentes da Universidade de Brasília, sendo que ao final da coleta, alguns questionários foram aplicados presencialmente, a fim de representar de forma adequada os diversos institutos e faculdades previstos no plano amostral. Para a análise dos dados, foi utilizado o Statistical Software for Social Sciences (SPSS), versão 20.0.

\section{Resultados}

De acordo com Laros (2004) o objetivo da redução de dados é possibilitar que uma grande quantidade de variáveis se reduza a um conjunto menor de índices sumários que tenham máxima variabilidade e fidedignidade.

As análises que podem ser utilizadas para a redução de dados são: análise dos componentes principais (ACP) e análise fatorial comum (AFC). A primeira consiste em um método que trabalha com a variância total observada; enquanto a segunda trabalha somente com a variância partilhada das variáveis. Tal fato redunda em que, no caso da ACP, os componentes estimados representam a variância das variáveis observadas da forma mais econômica possível. Ou seja, os componentes principais se tornam somas otimamente ponderadas das variáveis observadas. Já no caso da AFC os fatores podem ser considerados como os construtos latentes subjacentes às variáveis observadas (ver LAROS, 2004).

Para a verificação das evidências de validade de construto do instrumento, foi realizada a análise fatorial comum (AFC). Os passos a seguir foram seguidos.

\section{a) Decisão sobre o número de fatores}

A decisão sobre o número de fatores na análise se deu a partir da observância do gráfico scree plot. A indicação no gráfico scree plot, representado no Gráfico 2, indica a existência de 3 ou 4 fatores, determinados pelo ponto onde a curva desacelera e forma um "cotovelo". 


\section{Gráfico 2 - Scree plot para decisão sobre o número de fatores}

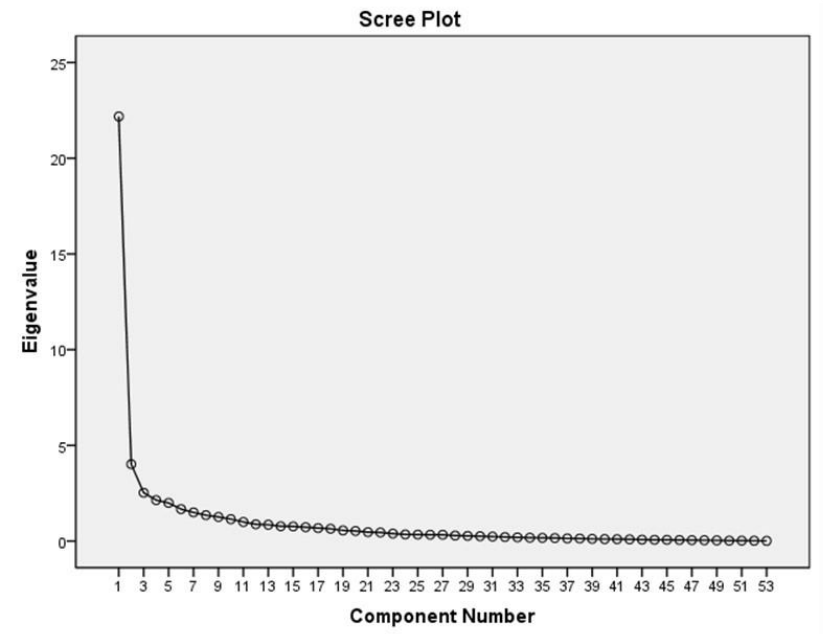

Fonte: Elaboração própria

Após análise pedagógica da estrutura composta por 4 fatores, optou-se por trabalhar com 3 fatores, haja vista um dos fatores, Planejamento e desenvolvimento institucional ter se apresentado com cargas fatoriais insatisfatórias (inferiores a 0,30), e o quarto fator encontrado foi a divisão da infraestrutura em duas facetas, sendo uma delas sobre biblioteca. Portanto, fez mais sentido pedagógico, para os fins desta pesquisa, não segmentar esse fator.

\section{b) Extração dos fatores}

A partir do procedimento PAF - Principal Axis Factoring ${ }^{3}$, critério de rotação $\operatorname{Promax}^{4}$ (Kaiser normalization, kappa=4), com solução convergente após 8 iterações, foram rotacionados os três fatores. Neste momento, as análises estarão adstritas às comunalidades, agora carregadas a partir de 3 fatores, e à Pattern Matrix, indicando o relacionamento das variáveis com os fatores por meio das cargas fatoriais. ${ }^{5}$

A Tabela 4 descreve os itens do questionário enumerados de forma hierarquizada, a partir das maiores cargas fatoriais para os 3 fatores.

\footnotetext{
${ }^{3} \mathrm{O}$ método PAF de extração de fatores utiliza os coeficientes de correlação como estimativas iniciais das comunalidades. Essas, por sua vez, são usadas para estimação das novas comunalidades. O método é iterativo e busca satisfazer o critério de convergência de extração.

${ }^{4}$ Usado para grandes grupos de dados e adequado para a identificação de fatores de segunda ordem.

${ }^{5}$ Os valores das cargas fatoriais abaixo de 0,32 foram desconsiderados.
} 
Tabela 4 - Cargas fatoriais obtidas a partir da solução com três fatores

\begin{tabular}{|c|c|c|c|}
\hline \multirow{2}{*}{ Itens } & \multicolumn{3}{|c|}{ Fator } \\
\hline & 1 & & 3 \\
\hline 1. Espaço físico destinado às aulas teóricas & 0,92 & & \\
\hline 2. Condições gerais dos auditórios & 0,86 & & \\
\hline 3. Espaço físico destinado às aulas práticas & 0,85 & & \\
\hline 4. Sala de professores & 0,83 & & \\
\hline 5. Serviços de apoio tecnológico para as aulas & 0,82 & & \\
\hline 6. Espaços destinados à orientação dos alunos & 0,79 & & \\
\hline 7. Infraestrutura física da biblioteca & 0,78 & & \\
\hline 8. Instalações sanitárias & 0,75 & & \\
\hline 9. Espaços de convivência e alimentação & 0,75 & & \\
\hline 10. Quantitativo de salas de aula & 0,74 & & \\
\hline 11. Serviços de apoio disponibilizados nos ambientes destinados às aulas práticas & 0,72 & & \\
\hline 12. Serviço de atendimento da biblioteca & 0,71 & & \\
\hline 13. Instalações administrativas do Instituto ou Faculdade & 0,70 & & \\
\hline 14. Convergência entre recursos didáticos disponíveis e as necessidades do docente & 0,68 & & \\
\hline 15. Grau de informatização da biblioteca & 0,66 & & \\
\hline $\begin{array}{l}\text { 16. Quantidade de itens (livros, periódicos, dvds, etc.) disponibilizados no acervo da } \\
\text { biblioteca. }\end{array}$ & 0,63 & & \\
\hline 17. Segurança no Campus & 0,61 & & \\
\hline 18. Razoabilidade na distribuição de alunos por sala & 0,59 & & \\
\hline 19. Grau de atualização do acervo da biblioteca & 0,57 & & \\
\hline 20. Estacionamento & 0,54 & & \\
\hline 21. Condições de Acessibilidade no Campus & 0,49 & & \\
\hline 22. Restaurante Universitário & 0,44 & & \\
\hline 1. Considero o modelo de autoavaliação institucional eficaz & & 0,92 & \\
\hline 2. Percebo que a instituição faz uso dos resultados das avaliações externas & & 0,91 & \\
\hline 3. O modelo de autoavaliação institucional é suficientemente conhecido & & 0,84 & \\
\hline $\begin{array}{l}\text { 4. Considero que na instituição há suficiente divulgação do Plano de Desenvolvimento } \\
\text { Institucional }\end{array}$ & & 0,79 & \\
\hline 5. A instituição possui valores bem definidos e consolidados & & 0,62 & \\
\hline 6. Percebo continuidade nas Políticas de Gestão & & 0,60 & \\
\hline 7. Conheço o PDI (Plano de Desenvolvimento Institucional) da UnB & & 0,58 & \\
\hline 8. Percebo na instituição uma rotina de normatização das práticas & & 0,55 & \\
\hline 9. Considero que existe um projeto universitário consolidado & & 0,51 & \\
\hline 10. Percebo um amadurecimento técnico na elaboração das políticas de gestão & & 0,51 & \\
\hline 11. Percebo clareza na definição de políticas acadêmicas institucionais & & 0,49 & \\
\hline $\begin{array}{l}\text { 12. As ações acadêmico-administrativas implantadas convergem com as políticas de } \\
\text { ensino para os cursos de graduação }\end{array}$ & & 0,47 & \\
\hline 13. Na instituição existe uma política acadêmica consolidada & & 0,43 & \\
\hline 14. Considero satisfatório o sistema de MençãoWeb & & 0,42 & \\
\hline 15. Considero que a instituição atende às expectativas da comunidade externa & & 0,41 & \\
\hline 16. O docente é incentivado a participar da definição das políticas de gestão & & 0,36 & \\
\hline 1. Considero os meios de comunicação da instituição eficazes. & & & 0,60 \\
\hline $\begin{array}{l}\text { 2. As ações acadêmico-administrativas implantadas são eficazes no apoio à realização } \\
\text { das ações de extensão (programas, projetos, atividades) }\end{array}$ & & & 0,59 \\
\hline $\begin{array}{l}\text { 3. As ações acadêmico-administrativas implantadas convergem com as políticas de } \\
\text { ensino para os cursos de pós-graduação }\end{array}$ & & & 0,58 \\
\hline $\begin{array}{l}\text { 4. As ações acadêmico-administrativas implantadas convergem com as políticas para a } \\
\text { pesquisa (programas, projetos e iniciação científica). }\end{array}$ & & & 0,54 \\
\hline $\begin{array}{l}\text { 5. Considero que existe coerência entre o plano de carreira implantado e a gestão do } \\
\text { corpo docente }\end{array}$ & & & 0,47 \\
\hline 6. Considero o modelo de gestão centralizado & & & 0,40 \\
\hline $\begin{array}{l}\text { 7. Considero que as atividades de ensino, pesquisa e extensão são igualmente } \\
\text { valorizadas }\end{array}$ & & & 0,39 \\
\hline $\begin{array}{l}\text { 8. Considero satisfatória a qualidade das ações de formação continuada destinadas aos } \\
\text { docentes }\end{array}$ & & & 0,38 \\
\hline 9. Há incentivo para publicações científicas. & & & 0,36 \\
\hline
\end{tabular}


10. Considero satisfatória a oferta de ações de formação continuada destinadas aos docentes

11. Tenho domínio sobre o Projeto-Político- Pedagógico do meu curso

12. Para todas as disciplinas que leciono elaboro o plano de ensino

13. Os programas de apoio aos estudantes funcionam de modo satisfatório.

Nota: Fator 1: Infraestrutura física; Fator 2: Planejamento, Avaliação, Desenvolvimento e Gestão institucional; Fator 3: Políticas acadêmicas e gestão do corpo docente.

A fidedignidade dos fatores foi verificada por meio do cálculo do índice de consistência interna. Para tanto, utilizou-se o alfa de Cronbach, apresentado na última linha da Tabela 5. Como pode ser verificado, todos os valores são adequados, superiores a 0,70 .

\section{c) Interpretação dos fatores}

Nomear um fator, segundo Hair et al. (2009, p. 145) observa, é "designar algum significado para o padrão de cargas fatoriais". Dessa forma, para o estudo em questão, os fatores 1, 2 e 3 foram nomeados como: Infraestrutura Física, Planejamento, Avaliação, Desenvolvimento e Gestão Institucional e Políticas Acadêmicas e Gestão do Corpo Docente.

A Tabela 4 revela que os itens "espaço físico destinado às aulas teóricas", "condições gerais dos auditórios" e "espaço físico destinado às aulas práticas” são os itens mais importantes para a interpretação do fator 1: Infraestrutura Física. O fator Infraestrutura Física pode ser interpretado desde o conceito amplo, que considera espaços no campus, como biblioteca, estacionamento e restaurante, espaços nos institutos e faculdades, instalações sanitárias e serviços de apoio, até conceitos de infraestrutura mais adstritos ao ambiente de sala de aula, como auditórios, espaços para aulas teóricas e práticas, sendo estes últimos mais relevantes para a análise da infraestrutura na universidade.

O fator Planejamento, Avaliação, Desenvolvimento e Gestão Institucional pode ser interpretado a partir do conceito da avaliação e seus resultados, em relação ao Plano de Desenvolvimento Institucional e quanto à concepção das políticas dentro da Universidade, sejam elas de pessoal ou de gestão.

Finalmente para o fator 3: Políticas Acadêmicas e Gestão do Corpo Docente, faz-se necessária, principalmente, a informação acerca dos itens: "eficácia dos meios de comunicação" e "ações acadêmico-administrativas para a pesquisa, pós-graduação e extensão". Os conceitos importantes para esse fator consideram ainda as políticas voltadas para o docente, em sua macro e microesfera. 
A Tabela 5, a seguir, apresenta a matriz de correlação entre os fatores e mostra que eles são bem correlacionados, o que confirma a boa escolha pelo método de rotação oblíqua Promax.

Tabela 5 - Matriz de correlação entre os fatores

\begin{tabular}{cccc}
\hline Fator & Infraestrutura física & $\begin{array}{c}\text { Planejamento, } \\
\text { avaliação e } \\
\text { desenvolvimento } \\
\text { institucional }\end{array}$ & $\begin{array}{c}\text { Políticas acadêmicas e } \\
\text { gestão do corpo } \\
\text { docente }\end{array}$ \\
\hline $\mathbf{1}$ & 1,00 & & \\
$\mathbf{2}$ & 0,64 & 1,00 & 1,00 \\
$\mathbf{3}$ & 0,54 & 0,52 & \\
\hline
\end{tabular}

Fonte: Elaboração própria

Além das análises referentes ao conteúdo realizadas previamente, a análise fatorial e o cálculo do coeficiente de fidedignidade corroboram as evidências de validade com base na estrutura interna do instrumento, o que possibilita o alcance do objetivo proposto nesse trabalho, já que possibilitou a identificação das combinações lógicas entre as variáveis para a redução das variáveis e obtenção dos fatores do instrumento (HAIR et al., 2009). Desse modo, construiuse um questionário, refinado e validado, com 51 itens, divididos em três fatores: Infraestrutura Física, Planejamento, Avaliação, Desenvolvimento e Gestão Institucional e Políticas Acadêmicas e Gestão do Corpo Docente.

\section{Conclusão}

As pesquisas que envolvem aplicação de questionários de adesão voluntária são conhecidas pela dificuldade prática que as acompanham. A não obrigatoriedade ou ausência de prêmio torna a vida do pesquisador especialmente complicada. O contato eletrônico fica sem resposta, a abordagem presencial é quase sempre desencontrada, os abordados se recusam a responder ou até mesmo se comprometem com o envio posterior e esse nunca chega. Essa dificuldade é ainda maior em pesquisas de Mestrado, onde há carência de recursos e tempo exíguo para a conclusão da pesquisa.

Surpreendentemente, não foi esse o caso da presente pesquisa. Não que a dificuldade tenha sido inexistente; no entanto, a alta adesão e a velocidade dos respondentes em muito superou as expectativas em relação à aplicação do questionário. O questionário de avaliação docente construído nos moldes do Sinaes e proposto por este trabalho foi respondido por mais de 300 docentes da Universidade de Brasília em apenas três dias. O que explicaria essa alta e rápida adesão? 
Primeiramente, nota-se a relevância do tema da pesquisa. Mas além disso, fica visível a insatisfação dos docentes com o processo de autoavaliação da Universidade de Brasília e sua ânsia por terem sua voz ouvida. Comentários recebidos que evidenciaram esse fato foram do tipo: "sua pesquisa é importante para a Universidade, respondi prontamente o questionário e estimularei firmemente meus colegas a preencherem o mesmo", "desejo arduamente que estes dados sejam amplamente divulgados e que sejam suporte para avaliação crítica das políticas educacionais desta Universidade", "parabéns pela pesquisa, espero que possa fornecer subsídios para a melhoria na UnB de várias das dimensões investigadas”. Foi com base nessa lacuna que a pesquisa foi realizada.

A educação superior no Brasil é um curioso campo de estudo, dado que se desenvolveu tardiamente, viveu um processo de acentuada expansão após o período da ditadura militar, e, paralelamente, uma tendência à privatização, o que fez deste campo objeto de variadas reformas, como as ocorridas em 1968, na década de 1990 e 2003.

Ao Estado, frente a esse cenário de expansão, coube a regulação do setor, com vistas ao controle de qualidade, tarefa essa incumbida, entre outras, à política da avaliação institucional. Sucessivas experiências de avaliação protagonizaram, desde a década de 1980, o cenário da educação superior no Brasil, a saber: o Programa de Avaliação da Reforma Universitária PARU, em 1983; o Grupo Executivo para a Reforma do Ensino Superior - GERES, instituído em 1985; o Programa de Avaliação Institucional das Universidades Brasileiras - PAIUB, de 1993; sucessor do PAIUB, o Exame Nacional de Cursos - ENC, ou "Provão", que constituiu a principal ferramenta dentro da política de avaliação da década de 1990; e o Sinaes, instituído em 2004 pela Lei ${ }^{\circ}$ 10.861. A política do Sinaes, no entanto, se distancia das demais desde a sua concepção. O Sinaes é um sistema de avaliação que busca unir todas as dimensões do ambiente da Universidade e, por isso, dotado de uma perspectiva mais global e integradora que as experiências anteriores. $\mathrm{O}$ sistema pode ser ainda considerado mais robusto e estável que os demais, tendo completado 11 anos de existência (POLIDORI; MARINHO-ARAUJO; BARREYRO, 2006).

A partir das exigências do Sinaes, entre as quais se destaca o envolvimento dos segmentos da comunidade acadêmica no processo de autoavaliação, a maior parte das universidades federais têm disponibilizado instrumento de consulta aos alunos, professores e técnicos, a fim de complementar o processo avaliativo. A UnB, no entanto, passou a fazê-lo somente a partir de 2015 e, ainda assim, de modo simbólico e improvisado.

Dessa maneira, o instrumento para o docente construído neste trabalho possui o arcabouço teórico e prático suficiente e necessário para ser utilizado pela Comissão Própria de 
Avaliação da UnB, a fim de que o processo de autoavaliação seja aperfeiçoado a partir de consulta direta ao corpo docente sobre as atividades desenvolvidas na Universidade.

As devolutivas da etapa de validação do questionário somaram 396 e a análise das mesmas permitiu verificar evidências de validade do instrumento proposto e sua boa interpretação a partir de três fatores: Infraestrutura Física, Planejamento, Avaliação e Desenvolvimento Institucional e Políticas Acadêmicas e Gestão do Corpo Docente.

Os 22 itens do fator Infraestrutura Física, os 16 itens do fator Planejamento, Avaliação, Desenvolvimento e Gestão Institucional e os 13 itens do fator Políticas Acadêmicas e Gestão do Corpo Docente, constituem escalas representativas dos fatores e apresentaram excelentes valores de consistência interna, aferida pelo coeficiente Alfa de Cronbach (0,95; 0,91 e 0,90, respectivamente).

Desenvolver um questionário de avaliação é uma tarefa complexa, dado que esse instrumento deve ser capaz de abordar as múltiplas dimensões do trabalho docente e do contexto em que se dá o processo de ensino e aprendizagem na Universidade. $\mathrm{O}$ desafio consiste em traduzir em itens os temas de relevância para o próprio docente avaliar suas necessidades dentro desse processo. Para lidar com essa dificuldade, foram utilizadas as técnicas do grupo focal e de análise de conteúdo feita por juízes - docentes doutores no tema da avaliação -, bem como a construção de escalas. A metodologia utilizada, portanto, priorizou a própria reflexão do docente a respeito do seu trabalho e do ambiente em que ele ocorre.

Todo instrumento educacional deve apresentar dados acerca do seu processo de validação, por isso a necessidade de submeter o questionário a esse processo. Num primeiro momento, as evidências de validade foram levantadas tendo como base o conteúdo do construto, que foi aprimorado pelo julgamento dos itens realizado por doutores no assunto e docentes da UnB e, portanto, sujeitos e alvo da pesquisa. Além disso, outra evidência de validade procede da estrutura interna, uma vez que se observou elevada consistência interna e a análise fatorial demonstrou uma estrutura adequada para o construto investigado. $\mathrm{O}$ instrumento demonstra evidências de validade, ainda, por abordar de forma compilada e estruturada os cinco eixos de avaliação do Sinaes - referência soberana no tema da avaliação da educação superior no Brasil.

O instrumento, dessa feita, está apto a ser incorporado ao processo de autoavaliação da Universidade de Brasília, com o qual poder-se-á disponibilizar, anualmente, consulta aos docentes acerca da Infraestrutura Física, Planejamento, Avaliação e Desenvolvimento Institucional e Políticas Acadêmicas e Gestão do Corpo Docente da UnB, o que certamente trará ganhos pedagógicos e estruturais para a universidade. 
A metodologia utilizada pode servir ainda para balizar o desenvolvimento de um instrumento de avaliação a ser respondido pelos servidores técnico-administrativos da Universidade, ou até mesmo pela sociedade civil, promovendo assim o envolvimento de todos os segmentos da comunidade acadêmica no processo de autoavaliação da UnB. Destaca-se, no entanto, que essa é uma ferramenta acessória no processo de autoavaliação, devendo ser consideradas outras formas de avaliação, para que, como um conjunto, a avaliação seja processada na Universidade de Brasília de modo completo.

\section{Referências}

BANDEIRA, M. L. et al. Avaliação da qualidade do ensino de pós-graduação: elementos para a construção e validação de um instrumento de pesquisa. In: ENANPAD, 22, 1998, Foz do Iguaçu. Anais... Rio de Janeiro: ANPAD, 1998.

BEDRITICHUK, A. G. A. Um instrumento de avaliação docente para a Universidade de Brasília: uma construção nos moldes do Sinaes. 2015. Dissertação (Mestrado em Educação) - Faculdade de Educação, Universidade de Brasília, Brasília, 2015.

BELLONI, I. et al. Avaliação Institucional da Universidade de Brasília. In: BALZAN, N. C.; SOBRINHO DIAS, J. (Orgs.). Avaliação institucional: teoria e experiências. 4. ed. São Paulo: Cortez, 2008.

BRASIL. Ministério da Educação. Nota Técnica INEP/DAES/CONAES n 65, 09 de outubro de 2014. Roteiro para relatório de autoavaliação institucional. Brasília, 2014.

COCHRAN, W. G. Sampling techniques. Wiley series in probability and mathematical statistics. 3. ed. New York: John Wiley, 1977.

DIAS SOBRINHO, J. Avaliação e transformações da educação superior brasileira (19952009): do Provão ao SINAES. Avaliação, Campinas; Sorocaba, v. 15, p. 195-224, 2010.

DAMÁSIO, B. F. Uso da análise fatorial exploratória em psicologia. Avaliação Psicológica, Itatiba, n. 2, v. 11, p. 213-228, ago. 2012.

HAIR, J. F. et al. Análise multivariada de dados. 6. ed. Porto Alegre: Bookman, 2009.

LAROS, J. A. O uso da análise fatorial: algumas diretrizes para pesquisadores. In:

PASQUALI, L. (Org.). Análise fatorial para pesquisadores. Petrópolis: Vozes, 2004.

MENEZES, A. M. Autoavaliação como instrumento de gestão na educação superior: o Caso do Instituto Federal de Educação, Ciência e Tecnologia de Goiás IFG. 2012. 175 f. Dissertação (Mestrado em Educação) - Universidade de Brasília, Brasília, 2012. Disponível em: <http://repositorio.unb.br/bitstream/10482/12342/1/2012_AngelaMariaMenezes.pdf $\geq$. Acesso em: 25 set. 2013.

QUEIROZ, Kelli C. A. L. Eu avalio, tu avalias, nós nos autoavaliamos?: uma experiência proposta pelo SINAES. In: CUNHA, C. da; SOUSA, J. V. de; SILVA, M. A. da (Orgs.).

Coleção Políticas Públicas de Educação. São Paulo: Autores Associados, 2011.

POLIDORI, M. M.; MARINHO-ARAUJO, C. M.; BARREYRO, G. B. SINAES:

Perspectivas e desafios na avaliação da educação superior brasileira. Ensaio, Rio de Janeiro, 
v. 14, n. 53, p. 425-436, 2006. Disponível em:

<http://www.scielo.br/pdf/ensaio/v14n53/a02v1453.pdf>. Acesso em: 19 fev. 2014.

RICHARDSON, R. J. (Cols.). Pesquisa social: métodos e técnicas. 3. ed. São Paulo: Atlas, 2014.

SANTOS, L. F. B. P. dos; LAROS, J. A. Avaliação da prática pedagógica do professor de ensino superior. Estudos em Avaliação Educacional, Brasília, n. 36, v. 18, p. 75-96, jan./abr. 2007.

${ }^{1}$ Girlene Ribeiro de Jesus

Universidade de Brasília |Faculdade de Educação Brasília |DF | Brasil. Contato: girlene.ribeiro@gmail.com

ORCIID (iD) https://orcid.org/0000-0002-1782-1089

${ }^{2}$ Amanda Guedes Andrade Bedritichuk Universidade de Brasília |Faculdade de Educação | Brasília | DF | Brasil. Contato: amandagandrade@gmail.com ORCIID (iD) https://orcid.org/0000-0001-5178-1570 